\title{
PEMBERDAYAAN TEMAN SEBAYA DALAM MENINGKATKAN PENGETAHUAN GIZI REMAJA KELEBIHAN BERAT BADAN
}

\author{
Retno Wahyuningsih ${ }^{1}$ \\ ${ }^{1}$ Jurusan Gizi, Poltekkes Kemenkes Mataram, Indonesia \\ Jl. Praburangkasari Dasan Cermen, Sandubaya Kota Mataram \\ Telp./Fax. (0370) 633837 \\ Email : khaylilaghina@gmail.com
}

\begin{tabular}{l} 
Article Info \\
\hline Article history: \\
Received July $14^{\text {th }}, 2020$ \\
Revised August $21^{\text {th }}, 2020$ \\
Accepte September $25^{\text {th }}, 2020$ \\
\hline
\end{tabular}

Keyword:

Intake; Knowledge;

Overweight; Peers

\section{Kata Kunci :}

Asupan; Kelebihan Berat Badan; Teman Sebaya; Pengetahuan

\begin{abstract}
Background : Being overweight in adolescents needs to be addressed early so as not to become a health problem in the future. Adolescents who are obese can be treated with peer education.
\end{abstract}

Methods : Quasi-experimental, randomized pre-post control group on 39 high school students aged 14-18 years were divided into two groups: 1) a treatment group with peer nutrition counseling, 2 control groups with classical counseling.

Results : Research that differentiates the knowledge before and after peer counseling (treatment group) with a significance of 0.000 ( $p$ $<0.05$ ), and the control group (classical counseling) with a significance of 0.001 ( $p<0.05)$.

Conclusion : Peer counseling can increase knowledge.

\begin{abstract}
ABSTRAK
Latar Belakang : Kelebihan berat badan pada remaja perlu diatasi sejak dini agar tidak menjadi masalah kesehatan kedepannya. Remaja yang mengalami obesitas bisa diterapi dengan pendidikan oleh teman sebaya.

Metode : Quasi experiment, randomized pre-post control group pada 39 siswa SMA usia 14-18 tahun dibagi menjadi dua kelompok : 1) kelompok perlakuan dengan penyuluhan gizi teman sebaya, 2 kelompok kontrol dengan penyuluhan secara klasikal.

Hasil : Terdapat perbedaan pengetahuan sebelum dan sesudah penyuluhan teman sebaya (kelompok perlakuan) dengan signifikansi $0,000$ ( $p<0,05)$, dan kelompok kontrol (penyuluhan klasikal) dengan signifikansi 0,001 $(p<0,05)$.

Kesimpulan : Penyuluhan teman sebaya dapat meningkatkan pengetahuan.
\end{abstract}

Copyright () Jurnal Gizi Prima All rights reserved.

\section{PENDAHULUAN}

Kelebihan berat badan saat ini menunjukkan angka prevalensi yang semakin meningkat. Hal ini ditunjukkan oleh data Riset Kesehatan Dasar (Riskesdas) 2013 bahwa sebanyak 26,6\% remaja usia $\geq 15$ tahun mengalami obesitas sentral. Adapun Riskesdas 2018 menunjukkan peningkatan remaja obesitas menjadi $31 \%$ dengan indikator pengukuran yang digunakan adalah lingkar perut. Di Provinsi Nusa Tenggara Barat angka obesitas remaja usia $\geq 15$ tahun adalah sebanyak $25 \%$ (Riskesdas, 2018).

Remaja yang mengalami kelebihan berat badan akan beresiko 30\% berlanjut mengalami kegemukan hingga 
masa usia dewasa. Kondisi kegemukan yang menetap pada remaja akan menjadi salah satu faktor resiko terhadap penyakit degeneratif (Simbolon et al., 2018). Kegemukan pada saat remaja selain menyebabkan gangguan pada kesehatan juga mempengaruhi perkembangan psikologis terutama mengganggu penampilan/ body image-nya.

Penyebab obesitas multifaktor yaitu melibatkan interaksi yang kompleks antara faktor genetik dan faktor lingkungan, seperti kurang aktivitas fisik, asupan makan, dan aspek-aspek sosial lainnya (Rolfes SR, 2013). Faktor kurang pengetahuan menjadi salah satu penyebab remaja memiliki kecenderungan memilih makanan yang kurang sehat bagi tubuhnya. Hal ini sesuai dengan penelitian Handayani pada anak SMA di Tangerang Selatan yang menunjukkan hasil terdapat angka kejadian obesitas lebih banyak dialami oleh siswa yang memiliki pengetahuan gizi rendah dan frekuensi konsumsi makanan dari jenis fast food dalam kategori sering (Handayani, 2018).

Kelebihan berat badan pada remaja dianggap lebih mudah ditangani dibandingkan dengan usia dewasa. Upaya penanganan gizi lebih pada remaja bisa dilakukan dengan beberapa cara, yakni pengaturan makanan, olahraga, maupun pendidikan gizi. Pendidikan gizi diberikan untuk meningkatkan pengetahuan dan kemampuan seseorang agar nantinya bisa memilih makanan yang bergizi dan sesuai dengan kebutuhan tubuh (Kahn,2006).

Dalam pergaulan sehari-hari, remaja memiliki hubungan yang erat dengan teman sebayanya. Hal ini tentunya juga akan berpengaruh juga terhadap perilaku remaja. Keterbukaan sesama remaja dapat menjadi peluang bagi upaya pengaturan makan remaja kegemukan terutama dalam hal memilih jenis makanan. Peran teman sebaya dapat digunakan sebagai upaya untuk meningkatkan pengetahuan gizi remaja kegemukan. Pengetahuan gizi yang diberikan adalah melalui penyuluhan gizi sebaya. Penyuluhan gizi sebaya adalah penyampaian /pemberian pesan, menanamkan keyakinan oleh teman sebaya kepada remaja dengan kelebihan berat badan agar bisa tahu, sadar, dan mengerti, serta bisa melaksanakan dengan baik anjuran gizi yang direkomendasikan untuk sesorang dengan kelebihan berat badan (Lestari, Dieny, 2016). Berdasarkan uraian yang di kemukakan tersebut, maka perlu dilakukan penanaman keyakinan pada remaja kelebihan berat badan melalui peran teman sebaya untuk meningkatkan pengetahuan gizi remaja obesitas.

\section{METODE PENELITIAN}

Penelitian ini berupa quasi exsperimental dengan rancangan randomized pre test-post test control group design. Subjek terdiri dua kelompok yaitu kelompok penyuluhan teman sebaya (KP1) dan kelompok kontrol (KP2). Penelitian dilakukan di SMAN 5 Mataram dan SMKN 1 Mataram. Waktu penelitian selama 1 bulan yaitu Agustus 2019. Data diolah dengan uji Paired t-test untuk mengetahui beda pengetahuan pada dua kelompok.

\section{HASIL DAN PEMBAHASAN PENELITIAN}

Tabel 1. Karakteristik Subjek Penelitian

\begin{tabular}{ccccccccc}
\hline \multirow{2}{*}{ Variabel } & \multicolumn{4}{c}{ Perlakuan } & \multicolumn{4}{c}{ Kontrol } \\
\cline { 2 - 9 } & Min & Max & Rerata & SD & Min & Max & Rerata & SD \\
\hline Umur (tahun) & 15 & 18 & 16,15 & 0,745 & 14 & 17 & 15.58 & 0.769 \\
TB $(\mathrm{cm})$ & 148 & 182 & 162,3 & 7,85 & 146.4 & 175.5 & 158.52 & 6.53 \\
BB Awal $(\mathrm{kg})$ & 59,6 & 115 & 77.86 & 14,25 & 56.6 & 111.1 & 74 & 12.763 \\
IMT $\left(\mathrm{kg} / \mathrm{m}^{2}\right)$ & 24.8 & 36.8 & 29.215 & 3.7754 & 24.1 & 44.6 & 29.83 & 4.7 \\
\hline
\end{tabular}

Tabel 1 menunjukkan bahwa rerata umur kelompok perlakuan yaitu 16,15 tahun dan 15,58 tahun pada kelompok kontrol. Rerata tinggi badan (TB) dan berat badan pada kelompok perlakuan lebih tinggi dibandingkan dengan kelompok kontrol. Sedangkan status gizi berdasarkan Indeks massa tubuh (IMT) pada kelompok kontrol lebih tinggi dibandingkan dengan kelompok perlakuan.

Untuk mengetahui ada atau tidaknya perbedaan pengetahuan sebelum dan sesudah perlakuan pada kedua kelompok, maka dilakukan pengujian paired sample t-test. Adapun uji beda pengetahuan sebelum dan sesudah pada kedua kelompok disajikan pada Tabel 2. 
Tabel 2. Hasil Uji Beda Pengetahuan Sebelum dan Sesudah Perlakuan

\begin{tabular}{cccccc}
\hline \multirow{2}{*}{ Kelompok } & Variabel & n & Rerata \pm SD & $\begin{array}{c}\text { Perbedaan } \\
\text { Rerata } \pm \text { SD }\end{array}$ & IK 95\% \\
\hline Perlakuan & $\begin{array}{l}\text { Pengetahuan Awal } \\
\text { Pengetahuan Akhir }\end{array}$ & 20 & $80.5 \pm 9.02$ & $7 \pm 4,97$ & $4,67-9,33$ \\
& Pengetahuan Awal & 19 & $75.79 \pm 11.46$ & $7.9 \pm 8.3858$ & $3.85291-$ \\
Kontrol & Pengetahuan Akhir & 19 & $83.68 \pm 7.234$ & & 0,001 \\
& & & & & \\
\hline
\end{tabular}

$\mathrm{p}=$ Uji paired sample t-test

Tabel 2 menunjukkan rerata peningkatan pengetahuan pada kelompok perlakuan yaitu 7 dengan signifikansi $0,000$ ( $\mathrm{p}<0,05)$, sehingga ada perbedaan pengetahuan sebelum dan sesudah penyuluhan teman sebaya. Sedangkan pada kelompok kontrol diketahui rerata peningkatan pengetahuan yaitu 7.9 dengan signifikansi $0,001(\mathrm{p}<0,05)$ sehingga dinyatakan ada perbedaan pengetahuan sebelum dan sesudah penyuluhan secara klasikal (kontrol).

Penyuluhan gizi yang dilakukan oleh teman sebaya merupakan salah satu cara pelayanan bantuan yang diberikan oleh teman sebayanya. Sebelum memberikan penyuluhan gizi, teman yang berperan sebagai teman sebaya tersebut terlebih dahulu diberikan pelatihan dasar terkait pengetahuan mengenai gizi untuk menjadi penyuluh sebaya. Tujuannya adalah agar teman sebaya tersebut dapat memberikan pelayanan dalam bentuk pemberi/penyampai pesan baik secara individu / kelompok kepada teman-temannya yang memiliki masalah kelebihan berat badan. Penyuluhan oleh teman sebaya saat ini telah banyak dipraktikkan pada berbagai bidang, namun dalam bidang kesehatan dan gizi masih dalam jumlah yang sedikit. Penelitian yang dilakukan ini, diharapkan bisa dijadikan sebagai alternatif penanganan masalah pada remaja dengan kelebihan berat badan, yakni untuk membantu pengaturan diet sehingga bisa mengubah asupan energi, karbohidrat, lemak dan serat menjadi lebih baik dan sesuai dengan pola makan yang seharusnya bagi remaja dengan kegemukan.

Penelitian ini menunjukkan hasil terdapat perbedaan pengetahuan sebelum dan sesudah penyuluhan, sehinggahal ini membuktikan bahwa teman sebaya memiliki peranan yang penting untuk bisa memperbaiki dan menanamkan keyakinan agar terjadi perubahan perilaku,sikap maupun pengetahuan terutama dalam hal pemilihan makanan sehinggaakan mampu mengubah status gizi kegemukan menjadi normal.

\section{KESIMPULAN}

Terdapat perbedaan pengetahuan sebelum dan sesudah penyuluhan teman sebaya (kelompok perlakuan) dan kelompok kontrol (penyuluhan klasikal) $(\mathrm{p}<0,05)$.

\section{SARAN}

Perlu diselenggarakan sosialisasi dan penyuluhan bagi remaja tentang peran teman sebaya dalam upaya meningkatkan pengetahuan remaja.

\section{DAFTAR PUSTAKA}

Handayani, Dian. 2018. Faktor Dominan Obesitas padaSiswa Sekolah Menengah Atas di Tangerang Selatan Indonesia. Jurnal Kedokteran dan Kesehatan, Vol. 14, No. 1, Januari 2018

Kahn R.F. 2006. Continuing Medical Education in Nutrition. American Journal of Clinical Nutrition. April. Vol. 83. No. 4. 981 S-984S.

Lestari, Dieny.2016. Pengaruh Konseling Gizi Sebaya terhadap Asupan Serat dan Lemak Jenuh pada Remaja Obesitas di Semarang. Journal Of Nutrition College Volume 5 No1.

Riset Kesehatan Dasar 2013. Kementerian Kesehatan Republik Indonesia

Riset Kesehatan Dasar 2018. Kementerian Kesehatan Republik Indonesia

Rolfes SR (2006) Understanding Normal and Clinical Nutrition (8th Ed)(gnv64).pdf. Eight Edit. Edited by Sarah Farriant. USA: Yolanda Cossio. 
ISSN : 2656 - 2480 (Online)

ISSN : 2355 - 1364 (Print)

Supariasa, IDN. 2012. Penilaian Status Gizi. EGC Jakarta. 